\title{
Re-Thinking Youth Suicide: Language, Culture, and Power
}

\author{
Jennifer White
}

School of Child and Youth Care

University of Victoria

Michael J Kral

School of Social Work

Wayne State University

\begin{abstract}
In this article we set out the context and provide the theoretical resources for re-thinking youth suicide as a sociocultural, political, and relational issue. Drawing on recent high profile youth suicides as reference points, we aim to illuminate some of the complex relational processes and sociopolitical conditions that may make some lives more 'unlivable' than others. We adopt a social constructionist perspective to argue that experiences of distress, understandings of self, and knowledge about suicide are not stable and objective entities awaiting discovery. Rather, they are brought into being through historically and culturally specific social practices, including language, discourse and relations of power. We then turn to more recently developed cultural frameworks and social justice orientations as a way of bringing the much neglected topics of culture and power into the scholarly conversation about youth suicide. We conclude by exploring some of the implications for practice and policy that might follow from these reformulations.
\end{abstract}

\section{Introduction}

We have witnessed an unprecedented number of high profile suicides among young people in recent years. For example, Port Coquitlam teenager Amanda Todd killed herself after enduring years of intimidation and on-line harassment. This included sexual exploitation, blackmail, and cruel attacks from strangers and peers. Weeks before her suicide she uploaded a nine-minute YouTube video to the Internet where she silently displayed a series of handwritten cards to give an account of her experience and ongoing suffering. This video went viral. Meanwhile Rehtaeh Parsons, a 17-year-old girl from Nova Scotia, died by suicide following repeated exposure to online harassment after pictures of her being sexually assaulted by four males were circulated on the Internet. In a final example, Jamie Hubley, a 15-year-old, openly gay student from Ottawa killed himself after being subjected to ongoing homophobic bullying. Prior to taking his own life he wrote, "This hurts too much," in his public blog. ${ }^{1}$

\footnotetext{
${ }^{1}$ For media accounts of these stories see http://news.nationalpost.com/2012/10/12/amanda-
} 
Each of these suicide deaths has been surrounded by a highly charged public commentary. We have chosen these particular cases to analyze because they shine the spotlight on a range of complex and challenging issues, including sexual violence, homophobia, and cyber bullying. While the unique circumstances and private histories of these young people are not fully known, it would appear that cruelty, violence, hatred, humiliation and shame (i.e., relational processes and sociopolitical contexts involving language, culture and power) provide some important connective threads. With this article we aim to illuminate some of the complex relational processes and sociopolitical conditions that may make some young lives more 'unlivable' than others (Cover, 2012). This way of thinking about youth suicide is in contrast to traditional psychological theories, which typically focus on individual personality traits, unmet psychological needs, mental health problems, or cognitive errors. Despite the value of some of these formulations, we argue that these approaches provide an excessively individualistic and technical account of suicide, which serves to both de-contextualize the act and strip away its inherently relational, ethical, historical, and political nature. It is time for alternative conceptualizations and approaches.

In this article we set out the context and provide the theoretical frames for re-thinking youth suicide as a sociocultural, political, and relational issue. We bring our experience as clinicians, researchers, educators, community activists, and suicide prevention advocates to the task of writing this article. It was our mutual experience of disenchantment with the standard approach to suicide prevention that united us in our attempts to seek out alternatives. While our primary interest is youth suicide, the ideas we discuss here are relevant for conceptualizing suicide across the lifespan. In the first part of the article we introduce a social constructionist perspective to show how taken-for-granted concepts and categories like depression, suicide, and self are not objective, self-evident entities awaiting discovery, but rather they are local forms of life that are brought into being through "historically and culturally situated social processes" (Gergen, 2011, p. 109). To showcase how some of these ideas might be productively put to work to begin re-thinking youth suicide, we draw on publicly available information surrounding the suicides of Amanda Todd and Rehtaeh Parsons, including newspaper interviews with the two girls' mothers about the circumstances leading up to their daughters' suicides.

In the second half of the article we turn to more recently developed cultural frameworks (Chu, et al, 2010; Colucci \& Lester, 2013; Kral, 1994; 1998) and social justice perspectives (Consoli, Casas, Cabrera \& Prado, 2012; Morrow \& Weisser, 2013; Reynolds, 2011) as a way of bringing the much neglected topics of culture and power into the scholarly conversation about youth suicide. Taken together these theoretical perspectives show the limits of individualistic, technical and biomedical formulations for conceptualizing mental health and suicide. They also pose a direct challenge to traditional Western notions of an independent, bounded, singular and static self, which in turn has implications for how concepts of distress and youth suicide might be theorized (Kirmayer, 2012; Marsh, 2010). Importantly, this orientation is not meant to

http://news.nationalpost.com/2013/06/02/ottawa-to-launch-national-anti-bullying-program-inwake-of-15-year-old-jamie-hubleys-suicide/ http://www.cbc.ca/news/canada/nova-scotia/rape-bullying-led-to-n-s-teen-s-death-says-mom1.1370780 
dispute the painful reality of youth suicide. It is however meant to show that our contemporary ways of making sense of youth suicide (i.e., the final act of a disordered and individual mind) are not natural, required, universal or fixed (Weinberg, 2009). In the final section of the paper, we explore some of the implications for practice and policy that might follow from these reformulations.

\section{A Constructionist Perspective on Youth Suicide}

The intellectual movement known as constructionism is vast and varied. Gubrium and Holstein (2008) use the phrase "constructionist mosaic" (p. 3) to capture the dynamism and diversity of the field, while also acknowledging the presence of a 'leading idea' which is that "...the world we live in and our place in it are not simply and evidently 'there' for participants. Rather, participants actively construct the world of everyday life and its constituent elements" (p. 3). A brief glance at the chapters included in the Handbook of Constructionist Research (Holstein \& Gubrium, 2008) confirms that a number of overlapping theoretical and methodological approaches (e.g., discursive constructionism, narrative constructionism, Foucauldian constructionism, etc.) can be housed under the broad 'constructionist banner.' Each strand has a rich history and all are expressed differently within specific intellectual traditions. For example, Foucauldian inspired approaches are typically focused on tracing and analyzing the historical emergence of dominant discourses (i.e., regimes of truth) and their constituting effects on selves and social worlds (Marsh, 2010), whereas other versions of constructionism such as discursive constructionism are more concerned with analyzing local and situated talk as it takes place within micro-level interactions (Gubrium \& Holstein, 2008). Meanwhile, narrative constructionism - itself a plurality of perspectives - typically foregrounds stories, dialogue, inter-personal processes of meaning making, and relational selves.

Social constructionist perspectives have been productively incorporated into a number of disciplines and professional practice arenas including anthropology, sociology, psychology, education, counseling, communication, nursing, public policy, management and organizational studies, and science and technology (Holstein \& Gubrium, 2008). We argue that it is time for suicidology to move beyond its narrow privileging of positivist methods of inquiry (Joiner, 2012), to embrace a broader range of theoretical and methodological approaches.

Generally speaking, constructionist approaches resonate with the diverse and contested intellectual terrain known as 'postmodernism' (McNamee \& Hosking, 2012). For example they typically challenge many of the taken for granted assumptions emerging out of the modernist Enlightenment period, including the valorization of individual rationality, the emphasis on empirical knowledge and the conceptualization of language as truthful representation (Gergen \& Thatchenkery, 1996). Weinberg (2008) adds that constructionism is a form of critical theory, directly challenging reification and disciplinary boundaries, seeking, "at least in part, to replace fixed, universalistic, and sociohistorically invariant conceptions of things with more fluid, particularistic, and sociohistorically embedded conceptions of them" (p. 14). Despite their theoretical and methodological variations, what constructionist approaches tend to share in common is a skepticism towards objective, value-free, acontexual knowledge or singular truths about reality. This is the point where we would like to begin. 
We draw on Gergen's (2011) recent articulation of social constructionist thinking to begin rethinking youth suicide. First, all knowledge is social and political. In other words, everything we take to be true or real emerges out of social and historical processes. Second, language and discourse are central to how we come to know and understand the world. In this way, language does not provide a mirror on reality but rather reality is constituted through ongoing language and social practices. Third, within a constructionist frame, a relational conceptualization of self comes to replace the traditional Western view of the individual mind and the bounded and autonomous self. As Gergen writes, "From this standpoint, it would not be selves who come together to form relationships, but relational process out of which the very idea of the psychological self could emerge" (p. 112). We hope to build on this idea by suggesting that it would not be individual selves who become depressed and decide to kill themselves, but cultural and relational processes out of which the very ideas of becoming depressed and killing oneself could emerge. This represents a significant shift in how youth suicide might be studied and theorized as it re-directs inquiry towards the process of "youth suicide" as a form of cultural life (Gergen \& Thatchenkery, 1996).

\section{Knowledge is Social and Political}

In general suicide has been understood in many different ways throughout human history. The Christian church officially disapproved of suicide in the $4^{\text {th }}$ century and legislated against it two centuries later. It was made illegal in England in 673 AD with a denial of burial of the body and the forfeiting of the suicide victim's property by the government (Szasz, 2002). During the $18^{\text {th }}$ century, courts increasingly found suicide verdicts to be non compos mentis (mentally unstable), and those who took their own lives were found not guilty. It came to be seen as a disease rather than a crime in 1763 (Colt, 1991) and suicides were then seen as victims (Minois, 1999). The idea of suicide shifted from being part of religious and legal discourses to becoming increasingly medicalized, first by the public and courts, and then by 1850 , by physicians (MacDonald, 1989). By 1844, psychiatry saw it as a "chronic disease of the brain" (Article I, 1844), and it became a symptom of mental illness in 1838 . While sociologists began to see suicide as caused by external social forces (Durkheim, 1951/1897; Morselli, 1882), psychiatry continued to see it as mental illness and caused by internal factors.

Today it is common to read that up to $90 \%$ of those who have died by suicide have a mental disorder at the time of their death, most likely depression (Bertolote, Fleischmann, De Leo, \& Wasserman, 2003; Hendriksson, Aro, \& Marttunen, 1993). For youth populations, the prevalence of psychiatric disorders among those who take their own lives are reported to be of a similar magnitude, with depression and substance abuse disorders most strongly associated with the outcome of suicide (Hawton, Saunders \& O'Connor, 2012).

Such claims provide an opportunity to show the social and political dimensions of knowledge. First, despite the fact that it is repeatedly cited throughout the suicidology literature, the assertion that $90 \%$ of suicide victims are mentally ill is highly questionable and warrants closer scrutiny. For the most part, such claims are informed by studies that rely on the psychological autopsy method. In this approach, grieving family members and friends (i.e., proxies) are interviewed about the person who killed him/herself and a mental health diagnosis is assigned retrospectively. As Hjemeland and colleagues (2012) make clear, there are a number of biases and methodological weaknesses associated with this method, leading to many questions about 
the validity of the findings. One of the most glaring problems is the assumption that a person's mental health status and/or psychiatric diagnosis can be determined by proxy.

Second, given the historically contingent and unstable definitions of suicide over time and across contexts (Marsh, 2010), official suicide statistics cannot be considered incontrovertible facts about the social world. They, too, are cultural products that are influenced by human interpretation and subjective processes. Suicide statistics often tell us more about the social practices, professional procedures, and authority of medical examiners than they reveal about the phenomenon of suicide itself (Timmermans, 2005). This is because the facts surrounding a suicide do not always speak for themselves. Rather, they are actively assembled based on current legal and forensic definitions of what is to count as a suicide. Social processes including the development of criteria and thresholds for classifying a death as a suicide, professional norms, and bureaucratic requirements all come into play.

Knowledge is thus an effect of power whereby certain groups of people are authorized to 'tell the truth' about suicide. Instead of seeing depression or anxiety as a rational or causal explanation for youth suicide, it can be useful to see how a range of human activities, including social, legal, psychiatric, forensic, pathological, media and statistical practices, interact to make suicide and mental health disorders knowable as objects of scientific study and analysis (Cover, 2012; Jaworski, 2003). In other words, all knowledge about suicide is social and political. This is because how we know exerts a strong influence on what can be known.

In the case of Amanda Todd, we know that her experiences of distress and ultimate suicide occurred within a local context that included interpersonal violence, harassment, and cruelty, all of which exist within a larger societal/cultural context of sexism, gender violence, misogyny, and the sexual objectification of girls' and women's bodies. This way of contextualizing and making sense of distress and youth suicide is largely absent from the mainstream suicidology literature where there has been an over emphasis on individual psychiatric disorders and other individual risk factors. Understandings of youth suicide are strongly influenced by how the problem has come to be framed and documented (White, 2012; White \& Stoneman, 2012). The selective attention given to some risk factors over others, the role of human interpretation in deciding what is to count as suicide, and the authority granted to certain groups such as researchers or other experts to make claims about 'what suicide is,' show how fluid the concept has been, how historically contingent, how culturally embedded, and how poorly understood. This offers good evidence of its socially constructed and political nature.

\section{Language and Discourse Shape Our Understandings of the World}

Rather than viewing language as a transparent medium that can accurately and faithfully represent reality, social constructionists argue that reality and forms of life are constituted through language and the availability of specific discourses. A constructionist view of reality is based on a performative view of language and regards all knowledge as local and contingent (Gergen, 2009). In short, language is action (Gergen \& Thatchenkery, 1996).

There has been an ongoing debate in the mainstream suicidology literature about whether suicide among youth should be framed as a response to stress or as evidence of a mental health problem (Lake et al., 2013). Despite this being an open question that has not been 
empirically resolved, and even the terms of the either/or question are predicated on certain assumptions that the social world is fully knowable, much of the recently published literature on school-based youth suicide prevention implies that the evidence linking youth suicide and mental illness is unequivocal (Aseltine \& DiMartino, 2004). This has the consequential effect of positioning suicidal and distressed young people as ill or not normal and in need of professional intervention. Within a constructionist view, such dominant language practices are not granted the status of truth, but rather are seen as one available discourse among many. In other words, things can always be otherwise (Gergen, 2001).

Meanwhile, a published newspaper article, which features interviews with the mothers of Amanda Todd and Rehtaeh Parsons, illustrates the role of language in constituting local realities. In the article "The problem with the term 'cyberbullying'2 (Offman, 2013), the mothers of Amanda Todd and Rehtaeh Parsons raise important questions about what to call what happened to their daughters. The existing term "cyberbullying," itself constructed over 15 years ago in response to a new Internet reality, is thought to be inadequate according to Amanda Todd's mother. She is quoted as saying, "This is about character defamation and social assassination," ... I'd call it cyber-harassment." The mother of Rehtaeh Parsons would prefer the term "harassment" to describe what happened to her daughter. She is quoted as saying, "She became the target, and once that happens it basically tears you down to the core of your being. In a time when you are forming who you are as a person, the social destruction of your very being is at stake." The generation of new descriptions (i.e., "social assassination" and "social destruction") in an attempt to adequately capture the violence done to their daughters highlights the instability of meaning, the role of language in constituting reality, and the impossibility of relying on singular categories or narrow frameworks for conceptualizing all youth suicides. Identities, knowledge, and attempts to secure meaning are actively being negotiated through language practices that are both flexible and consequential.

In a related point, White (2012) has recently drawn on a constructionist view to promote a more open, contextualized, and less standardized approach to youth suicide prevention practice. She carefully exposes many of the taken-for-granted assumptions of prevention programs that maintain the view of youth suicide as a stable, discrete, individual, problem that is amenable to scientific analysis and expert interventions. A recent qualitative study of schoolbased youth suicide prevention practices showed that programs often focus on the individual young person as the site of illness, irrational beliefs, accumulated stress and/or unmanaged emotions (White \& Morris, 2010; White, Morris \& Hinbest, 2012). In most cases, the onus for change is typically placed on young people to become better copers, problem-solvers, helpseekers and regulators of their own and others' distress. Few opportunities exist for young people to make sense of suicide and distress on their own terms as they are typically positioned as receivers of others' expert knowledge.

White (2012) argues for an expanded understanding of distress and youth suicide and suggests that when conceptualizations of risk move from being singularly located inside persons (i.e., GLBTQ youth) to the sociopolitical contexts that shape the conditions of possibility for young people (i.e., homophobia, narrow notions of masculinity), a more interesting and potentially

${ }^{2}$ http://www.theglobeandmail.com/news/national/the-problem-with-the-termcyberbullying/article14939234/?page=all 
fruitful prevention conversation is opened up. As Cover (2012) also suggests, we need more complex and dynamic frameworks for understanding youth suicide:

Suicide is not the outcome of depression/mental health problems nor the product of purely socio-environmental factors (homophobia or discrimination) but is a flight from unbearable pain for which some youth are vulnerable in terms of a vulnerability produced socially but which can produce mental health symptoms that sit alongside suicidality - not necessarily in a chain of causality (p. 14)

By re-thinking youth suicide in these ways a number of promising alternatives for responding become available, including those that recognize youth suicide within a culturally specific, relational and sociopolitical context.

\section{Relational Selves}

Western, liberal humanist views of selfhood are typically linked to autonomy, independence, boundedness, and stability (Sinclair, 2007). In such conceptualizations, there is a clear division between self and other. Such individualistic views of the self are largely taken for granted, even though in many cultures such a view is incompatible with more relational and collectivist understandings (Geertz, 1973; Gergen, 2011; Kirmayer, 2012). Not surprisingly, such a view of selfhood exerts a strong influence on how youth suicide is conceptualized and studied. Specifically, an essentialist, self-determining, independent self is understood to be 'behind the act' of youth suicide and this is presumably why we see so many psychological autopsy studies focused on identifying the psychopathologies, biological predispositions, personality traits and cognitive vulnerabilities which are presumed to exist within individuals.

In contrast, a relational view of self is predicated on the idea that we are all multiply, fluidly, and socially constituted. It is social, political and historical processes, including language, conventions, habits, and discourses, not individual minds, through which we become intelligible to ourselves and others (Gergen, 2011). In this way of thinking, language and selves are performative. To make this more concrete and to link it back to our interest in youth suicide, here is an example of how depression (and ultimately youth suicide) might be re-thought through a relational and culturally specific lens (Kleinman, 2004; Kleinman \& Good, 1985).

From the present [constructionist] standpoint depression is not an individual disorder; an individual "does depression" as a culturally intelligible action within a context of relationship. Therapeutic attention thus moves outward from the individual mind...to the relational scenarios in which the person is engaged. In what kinds of relationship is the depression invited, with whom, and under what conditions? (Gergen, 1999, p. 137)

Amanda Todd, like most of us living in the West, was born into a world where individuals are differentially advantaged along intersecting lines of age, gender, race, ability, sexual orientation and class. These variables hold "...a powerful influence over the plot of the stories by which people live" (Sinclair, 2007, p. 154). While we cannot know for sure what Amanda Todd lived through in the months leading up to her suicide, as members of this shared (patriarchal) culture, we can certainly imagine that her experience as a victim of sexual exploitation and blackmail led to social ostracism and contributed to a stigmatized identity. Within this particular 
cultural context, her social relations likely became increasingly rejecting and demeaning. Through the extensive digital footprint that Amanda Todd left behind, we see evidence of her resistance (i.e., using the cards to tell her story), and we also see her becoming an object of hatred. These relational realities and sociopolitical conditions likely provided fertile ground for the problems of depression, self-loathing, and hopelessness to take hold. While there were likely a whole host of other individual and social factors contributing to her suicidal thoughts and behaviors, our main point is that her experiences of distress, hopelessness and suicidal thoughts were socially, culturally and relationally mediated processes and responses. This way of thinking is quite distinct from a strictly psychological or biomedical understanding that views suicide as something conjured up and enacted by an individual human mind, a notion that Kral (1998) refers to as the "great origin myth within suicidology" (p. 229).

\section{Cultural Frameworks and Social Justice Perspectives}

Jamie Hubley, Amanda Todd, and Rehtaeh Parsons did not invent suicide as a response to suffering, but rather they drew on a long line of cultural and historical resources, received social logic, and available idioms of distress (Jaworski, 2003; Kral, 1994; Nichter,1981; 2010). Put simply, "Idioms of distress are socially and culturally resonant means of experiencing and expressing distress in local worlds" (Nichter, 2010, p. 405). Zayas and Gulbas (2012) note that "idioms of distress communicate something: they indicate to others in the individual's social world that something is amiss" (p. 722). In the case of Amanda Todd, using flashcards and social media to communicate that "something was amiss" was a "culturally resonant means of expressing distress" within our present globalized, digital culture. Suicide becomes an idiom of distress through normative reasons for suicide and methods for expression and carrying it out. Cluster suicides among young people are examples of this, when a number of youth in a setting copy each other in suicide over a brief period of time (Gould, Wallenstein, \& Davidson, 1989; Neizen, 2009, in press). That suicide takes on cultural forms tells us something about suicide beyond psychopathology, serotonin, and genetics. Suicide is a performance and a social act.

\section{Suicide as a Cultural Scheme}

Youth suicide rates and methods vary considerably across societies and yet a cultural view of suicide has been largely absent in suicidology (Colucci \& Lester 2013). Suicide manifests itself differently in different places. It is clear that culture influences the expression, even experience, of distress (Angel \& Thoits, 1987; Fenton, \& Sadiq-Sangster, 1996; Nichter, 1981; Takeuchi, Chun, Gong \& Shen, 2002). Our words and actions can only ever make sense within particular cultural traditions. To state "I am depressed" or "I am suicidal" is only meaningful within particular relational and cultural contexts (Gergen, 2011). For example, Kral (2012) shows how suicide among Inuit is embedded in family and romantic relationships that have changed dramatically, within a cultural context of colonialism.

Kral $(1994,1998)$ has proposed a cultural theory of suicide, which is relevant for re-theorizing youth suicide. He builds on an earlier view of suicide from Shneidman (1971) that relies on the necessary and sufficient components of perturbation and lethality. Perturbation refers to any form of distress. Suicide risk factors are linked to perturbation, not suicide. Kral shifted Shneidman's understanding of lethality (from the method of suicide or personality of the 
individual) to the cultural idea of death, and of suicide specifically, in response to perturbation. It is the idea of suicide where lethality resides. Ideas are cultural, they are relationally expressed, and they are socially constructed (Gergen, 2001; Hacking, 1999). This includes ideas about suicide (Niezen, in press). Building on this point Chu, Goldblum, Floyd and Bongar (2010) have developed a cultural model of suicide that shows how culture contributes to suicide through cultural sanctions or attitudes toward suicide, idioms of distress, subjective distress, and social discord.

In other words, the 'choice' of suicide as a way of responding to distress and upset is culturally conditioned and the suicides of Amanda Todd, Jamie Hubley, and Rehtaeh Parsons cannot be understood in the absence of reference to their relational embeddedness and their particular sociocultural situatedness. This requires paying attention to issues of gender, race, sexual orientation and age and the ways in which these fluid and intersecting identity markers interact within institutional relations of power and broader societal contexts of sexual violence, racism, homophobia, and discrimination.

\section{Social Justice Orientations}

We have already highlighted the ways in which experiences of distress, including hopelessness and suicidality, are socially and culturally constituted. Now we would like to address how social and historical contexts also produce environments of discrimination and social inequity, which place a disproportionate burden of suffering on some groups of people and not others (Morrow \& Weisser, 2012). It is well established that social and structural inequities have corrosive effects on the mental health and well-being of children, youth, families and communities. Adverse living conditions, socioeconomic disadvantage, unemployment and economic hardship all confer risks for suicide (Dupere, Leventhal \& Lacourse, 2009; Li, Page, Martin \& Taylor, 2011). Poverty and social fragmentation are linked to suicide (Bernburg, Thorlindsson, \& Sigfusdottir, 2009; Murali \& Oyebode, 2004; Rehkopf \& Buka, 2006; Whitley, Gunnell, \& Smith, 1999; Young, 1990), as are racism, prejudice, and discrimination (Clements-Nolle, Marx, \& Katz, 2006; Consoli, Casas, Cabrera \& Prado, 2012; Johnson, 1994; Meyer, 2003; Utsey, 1997; Williams, 1999). Historical postcolonial trauma contributes to Indigenous youth suicide and psychological distress (Brave Heart, 1999; Brave Heart-Jordan \& DeBruyn, 1995; Gone, 2013, Kral, 2012; Waldrum 2013). Meanwhile, there is a growing body of work that confirms that sexual minority youth (GLBTQ) are at increased risk for depression and suicidal behaviors compared with their heterosexual peers (Marshal, et al. 2011). Negative social responses, peer victimization, harassment and discrimination - which are all part of a broader pattern of societal homophobia - are thought to contribute to the elevated rates of suicidal behaviors among GLBTQ youth (Russell, 2005). Suicide is thus tied to social inequities and injustice. Framed thus, suicide prevention should also be directed toward social justice (Reynolds, 2011).

A social justice oriented approach to mental health and suicide prevention moves beyond the provision of individual interventions to include a focus on the fair and equitable distribution of societal resources so that all members of society can flourish (Morrow \& Weisser, 2012). It provides an opportunity for young people, many of whom occupy positions on the margins, to critically reflect on their experiences and take action in the world, based on the principles and practices of empowerment, collaboration, equitable access to resources, and local participation (Consoli, Casas, Cabrera \& Prado, 2012). In the final section, we highlight a number of 
promising approaches to youth suicide prevention practice that are inspired by these values and commitments.

\section{Implications for Practice and Policy}

What might an expanded, justice-oriented, participatory approach to youth suicide prevention look like? In this section we explore several promising actions that can be taken up within school, community, and policy contexts. The ideas and suggestions we articulate here are not meant to be prescriptive, but rather point towards a more ethically and socio-politically informed approach to youth suicide prevention.

\section{School-Based Programs}

Several authors have recently advocated for more flexibility in the design and delivery of youth suicide prevention programs. For example, Klimes-Dougan and colleagues (2013) suggest including more "preference-based approaches to suicide prevention" (p. 93) which emphasize youth choice, empowerment, and engagement. Similarly, Pisani and colleagues (2013) discuss the importance of building "option rich (OR) interventions" into youth suicide prevention programs, which "...means developing interventions that offer participants ongoing options for how they will participate, in terms of content, structure, breadth and depth" (p. 816).

In keeping with this call for greater flexibility, we recommend embracing multiple frameworks for making sense of youth distress and suicide that go beyond biomedical formulations and professional understandings. This means that cultural, social and political explanations of suicide can be actively encouraged and explored. Students can be invited to draw on their own experiences and ask questions about the benefits and limits of specific prevention approaches. Public high profile youth suicides, such as those we have included here, can be drawn on as useful case studies for learning and discussion. Specifically, students can be asked to consider "what has been left out" of various public accounts of youth suicides, thus learning that in many respects, "critical practice is the search for what is left outside the story" (Rossiter, 2005, p. 3). For example when individual 'depression' is centered as a dominant explanation (and sexism or hegemonic masculinity is obscured from view), what are some of the potential implications?

Students can be supported to generate ideas of their own for making sense of, responding to, and counteracting suicidal despair, in ways that need not conform to adults' pre-set categories (Cook-Sather, 2013). They can be invited to consider the role of dominant cultural discourses in shaping ideas about what counts as a good/normal/desirable life and the potential costs to those who find themselves outside the normative center. By learning how to engage in critical analysis students can be helped to see the ways that competing frameworks and discourses (e.g., psychiatric, biomedical, technical, political, social justice) produce multiple and competing forms of knowledge (Cover, 2012). Specific skills to be taught to students could include: critical thinking, questioning assumptions, collaborating, group decision-making, problem solving, imagining alternative futures, and organizing for social change.

By recognizing young people as active agents and authorities on their own lives (Ginwright \& Cammarotta, 2002), less emphasis can be placed on transmitting empirical knowledge or 'facts' 
about suicide to students and more emphasis can be given to creating pedagogical spaces which privilege storytelling, local knowledge generation and joint action (Consoli, Casas, Cabrera \& Prado, 2012; White, Morris \& Hinbest, 2011). While many well-known participatory action approaches (e.g., photovoice, digital storytelling and community mapping) have traditionally been used as research frameworks, we believe that they could be fruitfully reimagined as pedagogical tools for creatively and respectfully engaging young people as collaborators in advancing the goals of youth suicide prevention (White, 2014). For example, photovoice involves supplying young people with cameras so they can capture their everyday experiences through photographs (Wang, 2006). The process is based on the assumption that through the act of taking pictures, and participating in reflective dialogues with others, students can be empowered to critically read and transform their social contexts. Digital storytelling is another creative and strengths-based approach that is designed to be socially transformative and capitalizes on young peoples' existing skills with social technology. This approach has already been successfully implemented in Northwest Alaska where young people came together to create digital stories as part of a broader youth suicide prevention strategy (Wexler, Gubrium, Griffin, \& DiFulvio, 2013). Finally, the strategy of community mapping provides students with the opportunity to represent their perspectives about their communities in new and creative ways using mapping tools and other forms of graphic representation (Amsden \& VanWynsberghe, 2005). Emphasis is placed on mobilizing youth strengths, maximizing inclusion, and respecting differences. Community mapping holds great potential for advancing the goals of social justice and youth suicide prevention within particular local contexts.

\section{Community Contexts}

Comprehensive, multi-strategy, ecological-transactional approaches which are implemented across an array of settings and contexts and developed by/with local communities hold a great deal of promise for addressing youth suicide. Meanwhile, interventions that support the emergence of collaborative relationships between professionals and community members are strongly recommended (Durie \& Wyatt, 2013). While there are many good examples of locally developed youth suicide prevention strategies that are developed by and with community members (see for example Baber \& Bean, 2009), in this section we focus on youth suicide prevention efforts within Indigenous communities, given the disproportionately high levels of suicide among this group.

Indigenous communities have long been calling for self-determination and a reclaiming of control over their lives. Health Canada has recently responded to this call. Based on research showing that Aboriginal community control is an important form of suicide prevention (Chandler \& Lalonde, 1998; Kral \& Idlout, 2009), Health Canada has developed an Aboriginal suicide prevention policy that gives communities control over suicide prevention activities. Beginning in 2005, The National Aboriginal Youth Suicide Prevention Strategy (NAYSPS) has funded Aboriginal communities to develop and run their own suicide prevention programs (Kral et al., 2009). This is in contrast to the evidence-based intervention movement, where external programs are exported into these communities, with no consideration given to their cultural assumptions or relevance. Such standardized, top-down interventions have been shown to have limited efficacy in Aboriginal communities (Gone, 2008; Prussing, 2008). Preliminary evidence suggests that young Inuit people taking direct community action to address suicide has resulted in fewer suicides (Kral, 2012, Kral \& Idlout, 2009). Such a locally owned and community driven 
action approach sits in contrast to efforts that center on the expertise of adults and other specialists. For example, a youth group in one Inuit community opened a youth center, after which the suicides declined significantly. It is not clear why exactly the youth center worked. Was it because it gave youth a place to go, to socialize, to be with their friends? Or was it also a broader sense of youth in the community feeling a sense of accomplishment, as the adults and community agencies, even the Hamlet Council, made clear how much they valued what the youth had done in the community? Collective efficacy contributes to personal well being (Kral \& Idlout, 2009), and the youth in the community developed this sense of collective agency. It may be that youth benefitted without even going to the youth center, which was in fact a very small building that left room for only a few youth to visit at any one time. Further research will be required to better understand the specific processes and practices that may have contributed to the change.

\section{Policy Interventions}

There are a number of policy interventions that can advance the goals of youth suicide prevention. We highlight two in particular here. First, good evidence is starting to emerge which suggests that efforts designed to enhance the overall school climate, including the creation of Gay-Straight Alliances (GSA), and the development of explicit anti-bullying policies, can go a long way towards increasing students' experiences of safety, support and belonging, and can also reduce risks for suicide ideation and attempts among students (Saewyc, Konishi, Rose \& Homma, 2014). Such interventions are particularly salient for GLBTQ youth who often report being victimized and harassed and who typically report higher rates of suicidal behavior compared with their heterosexual peers. Interestingly, Saewyc and colleagues found that the presence of GSA's and explicit anti-homophobic bullying policies in schools, not only benefited GLBTQ youth but also appeared to be associated with reduced levels of suicide ideation and attempts among heterosexual boys, suggesting an overall protective effect.

Second, given that we live in a world marked by deep social and economic inequities, understanding the role that poverty, discrimination and social injustice play in exacerbating existing vulnerabilities is essential to any youth suicide prevention effort (Li, Page, Martin \& Taylor, 2011). Accumulating research on the social determinants of health, including income distribution, education, employment, early childhood development, and housing, has convincingly established the links between inequitable social arrangements, adverse living conditions and poor health outcomes, including mental health (Raphael, 2009). The neglect of these influential macro structures in the development of mental health promotion and youth suicide prevention strategies will mean they are bound to be inadequate. Policy level interventions and organizational cultures that explicitly target community relations and social conditions, and include social transformation as a goal (White, 2014), represent concrete examples for expanding current approaches to youth suicide prevention.

\section{Conclusion}

We have identified historical, social, and political approaches to youth suicide and youth suicide prevention. These perspectives have long been absent in the suicidology literature where academic cultural biases toward medicalization, positivist research methodologies and 
individualism have been privileged. As we have shown here, current knowledge about youth suicide is socially constructed. We have also highlighted its complexity by calling attention to its historically contingent, relationally situated, and culturally embedded qualities. At the present time, at least in the West, suicide represents a culturally resonant way of expressing distress. Youth suicide prevention programs have typically emphasized that suicide is linked to individual psychopathology, without attending to its social nature. It is recommended that an ecological, social justice framework be applied to the understanding of youth suicide, where multiple contexts and discourses actively shape experiences of distress and suffering and need to be mobilized toward suicide prevention. Language, culture and power have all been under accounted for in the suicidology literature to date and we have sketched out some possibilities for a richer theorization of youth suicide, with implications for policy and practice.

\section{Contact Information:}

Jennifer White

School of Child and Youth Care

University of Victoria

Email: jhwhite@uvic.ca

\section{References}

American Psychiatric Association (2013). Diagnostic and statistical manual of mental disorders ( $5^{\text {th }}$ ed.). Arlington, VA: American Psychiatric Publishing.

Amsden, J. \& VansWynsberghe, R. (2005). Community mapping as a research tool with youth. Action Research, 3(4), 357-381. doi: 10.1177/1476750305058487

Angel, R., \& Thoits, P. (1987). The impact of culture on the cognitive structure of illness. Culture, Medicine and Psychiatry, 11, 465-494.

Article I (no author). 1844. Definition of insanity - Nature of the disease. The American Journal of Insanity 1: 97-116.

Aseltine, R. \& DiMartino, R. (2004). An outcome evaluation of the SOS suicide prevention program. American Journal of Public Health, 94, 446-451.

Baber, K. \& Bean, G., (2009). Frameworks: A community based approach to preventing youth suicide. Journal of Community Psychology, 37(6), 684-696.

Berger, J. (2013). Contagious: Why things catch on. New York, NY: Simon \& Schuster.

Bernal, M., Haro, J. M., Bernert, S., Brugha, T., de Graaf, R., Bruffaerts, R., Lepine, J. P., de Girolamo, G., Vilagut, G., Gasquet, I., Torres, J. V., Kovess, V., Heider, D., Neeleman, J., Kessler, R., \& Alonso, J. (2007). Risk factors for suicidality in Europe: Results from the ESEMED study. Journal of Affective Disorders, 101, 27-34. 
Bernburg, J. G., Thorlindsson, T., \& Sigfusdottir, I. D. (2009). The spreading of suicidal behavior: The contextual effect of community household poverty on adolescent suicidal behavior and the mediating role of suicide suggestion. Social Science and Medicine, 68, 380-389.

Bertolote, J. M., Fleischmann, A., De Leo, D., \& Wasserman, D. (2003). Suicide and mental disorders: Do we know enough? British Journal of Psychiatry, 183, 382-383.

Bohannon, P. (1960). Patterns of murder and suicide. In P. Bohannon (Ed.), African homicide and suicide, (pp. 230-266). Princeton, NJ: Princeton University Press.

Brave Heart, M. Y. H. (1999). Oyate ptayela: Rebuilding the Lakota Nation through addressing historical trauma among Lakota parents. Journal of Human Behavior in the Social Environment, 2, 109-126.

Brave Heart-Jordan, M. Y. H., \& DeBruyn, L. (1995). So she may walk in balance: Integrating the impact of historical trauma in the treatment of Native American Indian women. In J. Adelman \& G. Enguidanos (Eds.), Racism in the lives of women: Testimony theory and guides to anti-racist practice (pp. 345368). New York, NY: Haworth.

Breault, K.D. (1994). Was Durkheim right? A critical survey of the empirical literature on Le Suicide. In D. Lester (Ed.), Emile Durkheim Le Suicide: 100 years later (pp. 11-29). Philadelphia, PA: The Charles Press.

Brown, G. K., Beck, A. T., Steer, R. A., \& Grisham, J. R. (2000). Risk factors for suicide in psychiatric outpatients: A 20-year prospective study. Journal of Consulting and Clinical Psychology, 68, 371-377.

Cátedra, M. 1992. This world, other worlds: Sickness, suicide, death, and the afterlife among the Vaqueiros de Alzada of Spain. Trans. William A. Christian, Jr. Chicago: University of Chicago Press.

Chu, J.P., Goldblum, P., Floyd, R., \& Bongar, B. (2010). The cultural theory and model of suicide. Applied and Preventive Psychology, 14, 25-40.

Clark, Terry N. (1969). Gabriel Tarde: On communication and social influence. Chicago, IL: University of Chicago Press.

Clements-Nolle, K., Marx, R., \& Katz, M. (2006). Attempted suicide among transgender persons: The influence of gender-based discrimination and victimization. Journal of Homosexuality, 51, 53-69.

Colt, G. H. 1991. The enigma of suicide. New York, NY: Touchstone. 
Colucci, E. \& D. Lester (Eds.), Suicide and culture: Understanding the context. Cambridge, MA: Hogrefe.

Consoli, M., Casas, J.M., Cabrera, P. \& Prado, G. (2012). The Santa Barbara wellness project. Journal for Social Action in Counseling and Psychology, 4(1), 69-82.

Conwell, Y., Duberstein, P. R., \& Caine, E. D. (2002). Risk factors for suicide in later life. Biological Psychiatry, 52, 193-204.

Cook-Sather, A. (2012). Translating learners, researchers and qualitative approaches through investigations of students' experiences in schools. Qualitative Research, 13(3), 352-367.

Cover, R. (2012). Queer youth suicide, culture and identity: Unliveable lives? Surrey, UK: Ashgate.

Dautenhahn, K., \& Nehaniv, C. L. (2002). The agent-based perspective on imitation. Cambridge, MA: MIT Press.

Duberstein, P. R., Conwell, Y., Conner, K. R., Eberly, S., Evinger, J. S., \& Caine, E. D. (2004). Poor social integration and suicide: Fact or artifact? A case-control ctudy. Psychological Medicine, 34, 1331-1337.

Dupere, V., Leventhal, T. \& Lacourse, E. (2009). Neighborhood poverty and suicidal thoughts and attempts in late adolescence. Psychological Medicine, 39, 1295-1306.

Durie, R. E., \& Wyatt, K. (2013). Connecting communities and complexity: A case study in creating the conditions for transformational change. Critical Public Health, 23(2), 174-187.

Durkheim, E. 1951. Suicide: A study in sociology. Trans. J. A. Spaulding and G. Simpson. Glencoe, IL: The Free Press. Original publication 1897.

Farberow, Norman L. 1975. Cultural history of suicide. In N. L. Farberow (Ed.), Suicide in different cultures, (pp. 1-15). Baltimore, MD: University Park Press.

Fenton, S., \& Sadiq-Sangster, A. (1996). Culture, relativism and the expression of mental distress: South Asian women in Britain. Sociology of Health and IIIness, 18, 66-85.

Geertz, C. (1973). The interpretation of cultures. New York, NY: Basic.

Gergen, K. (1999). An invitation to social construction. London: Sage Publications.

Gergen, K. (2001). Social construction in context. London: Sage Publications.

Gergen, K. (2009). Relational being: Beyond self and community. New York: Oxford University Press.

Gergen, K. (2011). The self as social construction. Psychological Studies, 56(1), 108-116. 
Gergen, K. \& Thatchenkery, T. (1996). Organization science as social construction: Postmodern potentials. Journal of Applied Behavioral Science, 32, 356-377.

Ginwright, S., \& Cammarota, J. (2002). New terrain in youth development: The promise of a social justice approach. Social Justice, 29, 82-95.

Gone, J. P. (2008). Mental health discourse as Western cultural proselytization. Ethos, 36, 310-315.

Gone, J. P. (in press). Redressing First Nations historical trauma: Theorizing mechanisms for Indigenous culture as mental health treatment. Transcultural Psychiatry.

Gould, M.S. (2006). Suicide and the media. Annals of the New York Academy of Sciences, 932, 200-224.

Gould, M. S., Wallenstein, S., \& Davidson, L. (1989). Suicide clusters: A critical review. Suicide and Life-Threatening Behavior, 19, 17-29.

Hawton, K. , Saunders, K. \& O'Connor, R. (2012). Self-harm and suicide in adolescents. Lancet, $379,2373-2382$.

Hacking, I. (1999). The social construction of what? Cambridge, MA: Harvard University Press.

Heikkinen, M., Aro, H, \& Lonnqvist, J. (1993). Life events and social support in suicide. Suicide and Life-Threatening Behavior, 23, 343-358.

Hjelmeland, H., Dieserud, G., Dyregrov, K., Knizek, B. L., \& Leenaars, A. A. (2012). Psychological autopsy studies as diagnostic tools: Are they methodologically flawed? Death Studies, 36, 605-626.

Holstein, J. A., \& Gubrium, J. F. (2008). Handbook of constructionist research. New York, NY: Guilford.

Harre, R., \& Parrott, W. G. (1996). The emotions: Social, cultural and biological dimensions. Thousand Oaks, CA: Sage.

Gergen, K. J. (2009). Relational being: Beyond self and community. New York, NY: Oxford University Press.

Gergen, K. J. (2011). The self as social construction. Psychological Studies, 56, 108-116.

Gubrium, J. F., \& Holstein, J. A. (2008). The constructionist mosaic. In J. A. Holstein \& J. F. Grubrium (Eds.), Handbook of constructionist research (pp. 3-12). New York, NY: Guilford. 
Headly, Lee A. 1983. Suicide in Asia and the Near East. Berkeley \& Los Angeles, CA: University of California Press.

Hendriksson, M. M., Aro, H. M., \& Marttunen, M. J. (1993). Mental disorders and comorbidity in suicide. American Journal of Psychiatry, 150, 935-940.

Jaworski K. (2003). Suicide and gender: Reading suicide through Butler's notion of performativity. Journal of Australian Studies, 27, 137-146.

Johnson, D. (1994). Stress, depression, substance abuse, and racism. American Indian and Alaska Native Mental Health Research, 6, 29-33.

Joiner, T. (2011). Editorial: Scientific rigor as the guiding heuristic for SLTB's editorial stance. Suicide and Life Threatening Behavior, 41(5), 471-473.

Kirmayer, L. (2012). Cultural competence and evidence-based practice in mental health: Epistemic communities and the politics of pluralism. Social Science \& Medicine, 75, 249256.

Kleinman, A. (2004). Culture and depression. New England Journal of Medicine, 351, 951-953.

Kleinman, A., \& Good, B. (1985). Culture and depression: Studies in the anthropology and cross-cultural psychiatry of affect and disorder. Berkeley, CA; University of California Press.

Kral, M. J. (1994). Suicide as social logic. Suicide and Life-Threatening Behavior, 24, 245-255.

Kral, M.J. (1998). Suicide and the internalization of culture: Three questions. Transcultural Psychiatry, 35, 221-233.

Kral, M.J., \& Idlout, L. (2009). Community wellness and social action in the Canadian Arctic: Collective agency as subjective well-being. In L. K. Kirmayer \& G. G. Valaskakis (Eds.), Healing traditions: The mental health of Aboriginal peoples in Canada (pp. 315-334). Vancouver, BC: University of British Columbia Press.

Kral, M. J., Wiebe, P. K., Nisbet, K., Dallas, C., Okalik, L., Enuaraq, N., \& Cinotta, J. (2009). Canadian Inuit community engagement in suicide prevention. International Journal of Circumpolar Health, 68, 292-307.

Kral, M. J. (2012). Postcolonial suicide among Inuit in Arctic Canada. Culture, Medicine and Psychiatry, 36, 306-325.

Lake, A., Kandasamy, S., Kleinman, M. \& Gould, M. (2013). Adolescents' attitudes about the role mental illness in suicide, and their association with suicide risk. Suicide and Life Threatening Behavior,43(6), 692-703. doi: 10.1111/sltb.12052 
Lambert, M. J., \& Barley, D. E. (2001). Research summary on the therapeutic relationship and psychotherapy outcome. Psychotherapy: Theory, Research, Practice, Training, 38, 357361.

Li, Z., Page, A. Martin, G. \& Taylor, R. (2011). Attributable risk of psychiatric and socioeconomic factors for suicide from individual-level, population-based studies: $A$ systematic review, Social Science \& Medicine, 72, 608-616.

MacDonald, M. (1989). The medicalization of suicide in England: Laymen, physicians, and cultural change, 1500-1870. The Milbank Quarterly, 67 (Suppl. 1), 69-91.

Martin, D. J., Garske, J. P., \& Davis, M. K. (2000). Relation of the therapeutic alliance and other variables: A meta-analytic review. Journal of Consulting and Clinical Psychology, 68, 438-450.

McKenzie, N., \& Keane, M. (2007). Contribution of imitative suicide to the suicide rate in prisons. Suicide and Life-Threatening Behavior, 37, 538-542.

Meyer, I. H. (2003). Prejudice, social stress, and mental health in lesbian, gay, and bisexual populations: Conceptual issues and research evidence. Psychological Bulletin, 129, 674-697.

Minois, Georges. 1999. History of suicide: Voluntary death in Western culture. Trans. Lydia G. Cochrane. Baltimore, MD: John Hopkins University Press.

Morrow, M. \& Weisser, J. (2012). Towards a social justice framework of mental health recovery. Studies in Social Justice, 6(1), 27-43.

Morselli, Henry. 1882. Suicide: An essay on comparative moral statistics. New York, NY: D. Appleton and Company.

Moscicki, E. K. (1997). Identification of suicide risk factors using epidemiologic studies. Psychiatric Clinics of North America, 20, 499-517.

Murali, V., \& Oyebode, F. (2004). Poverty, social inequality, and mental health. Advances in Psychiatric Treatment, 10, 216-224.

Nichter, M. (1981). Idioms of distress: Alternatives in the expression of psychosocial distress: A case study from South India. Culture, Medicine and Psychiatry, 5, 379-408.

Neizen, R. (2009). Suicide as a way of belonging: Causes and consequences of cluster suicides in Aboriginal communities. In L. J. Kirmayer \& G. G. Valaskakis (Eds.), Healing traditions: The mental health of Aboriginal peoples in Canada (pp. 178195). Vancouver, BC: University of British Columbia Press.

Neizen, R. (in press). The Durkheim-Tarde debate and the social study of Aboriginal youth suicide. Transcultural Psychiatry. 
Offman, C. (2013). The problem with the term 'cyberbulling'. The Globe and Mail. Retrieved from http://www.theglobeandmail.com/news/national/the-problem-with-the-termcyberbullying/article14939234/?page=all

Phillips, Michael R., Xianyun Li, and Yanping Zhang. 2002. Suicide rates in China, 1995-99. The Lancet, 359, 835-840.

Prussing, E. (2008). Sobriety and its cultural politics: An ethnographer's perspective on "culturally appropriate" addiction services in Native North America. Ethos, 36, 354-375.

Raphael, D. (2009). Restructuring society in the service of mental health promotion: Are we willing to address the social determinants of mental health. International Journal of Mental Health Promotion, 11(3), 18-31.

Raphael, D. (2011). A discourse analysis of the social determinants of health. Critical Social Policy, 21(2), 221-236.

Rehkopf, D. H., \& Buka, S. L. (2006). The association between suicide and the socioeconomic characteristics of geographical areas: A systematic review.

Psychological Medicine, 36, 145-157.

Reynolds, V. (2011). Hate kills: Justice doing as a response to suicide. Keynote address at the Canadian Association of Suicide Prevention Conference, Vancouver, British Columbia.

Rizzolatti, G. (2005). The mirror neuron system and imitation. In S, Hurley \& N. Chater (Eds.), Perspectives on imitation: From neuroscience to social science. Vol. 1. Mechanisms of imitation and imitation in animals (pp. 55-76). Cambridge, MA: MIT Press.

Romer, D., Jamieson, P. E., \& Jamieson, K. H. (2006). Are news reports of suicide contagious? A stringent test in six U.S. cities. Journal of Communication, 56, 253-270.

Rossiter, A. (2005). Discourse analysis in critical social work: From apology to question. Critical Social Work, 6(1), Retrieved from http://www.uwindsor.ca/criticalsocialwork/2005volume-6-no-1

Saewyc, E., Konishi, C., Rose, H. \& Homma, Y. (2014). School-based strategies to reduce suicidal ideation, attempts, and discrimination among sexual minority and heterosexual adolescents in Western Canada. International Journal of Child, Youth \& Family Studies, $15(1), 89-112$.

Sahlins, M. (1985). Islands of history. Chicago, IL: University of Chicago Press.

Schonpflug, U. (Ed.). (2009). Cultural transmission: Psychological, developmental, social, and methodological aspects. Cambridge, UK: Cambridge University Press. 
Shirk, S. R., \& Karver, M. (2003). Prediction of treatment outcome from relationship variables in child and adolescent therapy: A meta-analytic review. Journal of Consulting and Clinical Psychology, 71, 452-464.

Shneidman, E. S. (1971). Perturbation and lethality as precursors of suicide in a gifted group. Suicide and Life-Threatening Behavior, 1, 23-45.

Shneidman, Edwin S. 1985. Definition of suicide. New York, NY: Wiley.

Sinclair, S. (2007). Back in the mirrored room: The enduring relevance of discursive practice. Journal of Family Therapy, 29, 147-168.

Stack, S. (2005). Suicide in the media: A quantitative review of studies based on nonfictional stories. Suicide and Life-Threatening Behavior, 35, 121-133.

Stack, S., \& Kposowa, A. J. (2008). The association of suicide rates with individual-level suicide attitudes: A cross-national analysis. Social Science Quarterly, 89, 39-59.

Steele, M. \& Doey, T., (2007). Suicidal behaviour in children and adolescents. Part 1: Etiology and risk factors. Canadian Journal of Psychiatry, 52, 21S-33S.

Stewart-Withers, R. R., \& O'Brien, A. P. (2006). Suicide prevention and social capital: A Samoan perspective. Health Sociology Review, 15, 209-220.

Szasz, Thomas. 2002. Fatal freedom: The ethics and politics of suicide. Syracuse, NY: Syracuse University Press.

Takeuchi, D. T., Chun, C-A, Gong, F., \& Shen, H. (2002). Cultural expressions of distress. Health, 6,221-236.

Tarde, G. (1903). The laws of imitation. New York, NY: Henry Holt and Company.

Tarde, G. (1904). La logique sociale. Paris: Félix Alcan.

Timmerman, S. (2005). Suicide determination and the professional authority of medical examiners. American Sociological Review, 70, 311-333.

Utsey, S. O. (1997). Racism and the psychological well-being of African American men. Journal of African American Men, 3, 69-87.

Vera, E. M., \& Speight, S. L. (2003). Multicultural competence, social justice, and counseling psychology: Expanding our roles. The Counseling Psychologist, 31, 253-272.

Waldrum, J. B. (in press). Healing history? Aboriginal healing, historical trauma, and personal responsibility. Transcultural Psychiatry. 
Wang, C. (2006). Youth participation in photvoice as a strategy for community change. Journal of Community Practice, 14(1), 147-161. doi:10.1300/J125v14n01_09

Wexler, L. M., \& Gone, J. P. (2012). Culturally responsive suicide prevention in Indigenous communities: Unexamined assumptions and new possibilities. American Journal of Public Health, 102, 800-806.

Wexler, L., Gubrium, A., Griffin, M. \& DiFulvio, G. (2013). Promoting positive youth development and highlighting reasons for living in Northwest Alaska through digital storytelling. Health Promotion Practice, 14, 617-623. doi: 10.1177/1524839912462390

White, J. (2012). Youth suicide as a 'wild problem:' Implications for prevention practice. Suicidology Online, 3, 42-50.

White, J. (2014). Expanding and democratizing the youth suicide prevention agenda: Youth participation, cultural responsiveness and social transformation. Canadian Journal of Community Mental Health, 33(1), 95-107. doi: 10.7870/cjcmh-2014-009

White, J. \& Morris, J. (2010). Precarious spaces: Risk, responsibility and uncertainty in youth suicide prevention education. Social Science \& Medicine, 71, 2187-2194.

White, J., Morris, J., \& Hinbest, J. (2012). Collaborative knowledge-making in the everyday practice of youth suicide prevention. International Journal of Qualitative Studies in Education, 25(3), 339-355.

White, J. \& Stoneman, L. (2012). Thinking and doing prevention: A critical analysis of contemporary youth crime and suicide prevention discourses. Child and Youth Services, 33, 104-126.

Whitley, E., Gunnell, D., Dorling, D., \& Smith, G. D. (1999). Ecological study of social fragmentation, poverty, and suicide. British Medical Journal, 319, 1034-1037

Wienberg, D. (2008). The philosophical foundations of constructionist research. In J. A. Holstein \& J. F. Grubrium (Eds.), Handbook of constructionist research (pp. 13-40). New York, NY: Guilford.

Williams, D. R. (1999). Race, socioeconomic status, and health: The added effects of racism and discrimination. Annals of the New York Academy of Sciences, 896, 173-188.

Young, T. J. (1990). Poverty, suicide and homicide among Native Americans. Psychological Reports, 67, 1153-1154. 